\title{
PERSEPSI PERAWAT TERHADAP PERAN APOTEKER DALAM PELAYANAN KEFARMASIAN DI RUMAH SAKIT ROBERT WOLTER MONGISIDI MANADO
}

\author{
NURSE'S PERCEPTIONS TOWARD THE ROLES OF \\ PHARMACISTS IN PHARMACEUTICAL CARE AT \\ ROBERT WOLTER MONGISIDI HOSPITAL \\ MANADO
}

\author{
Ni Made Dadiani ${ }^{1}$, Widya Astuty Lolo ${ }^{1)}$, Irma Antasionasti ${ }^{1)}$ \\ ${ }^{1)}$ Program Studi Farmasi FMIPA UNSRAT Manado, 95115
}

\begin{abstract}
Pharmacy services was one of the supporting activities of health services quality. Majority, the hospitals in Indonesia had not performed Pharmaceutical Care activities in accordance with the Standard of Pharmaceutical Care in Hospital stipulated in regulation of the Minister of Health Republic of Indonesia No. 72 year 2016. The lack of cooperation and communication between pharmacists, nurses and other health workers can cause differences in perception. This studied aims to know the opinions and expectations of nurse to the role of pharmacist in pharmaceutical care at Robert Wolter Mongisidi Hospital Manado. This research was a quantitative descriptive study and data collection tool used was a questionnaire about the opinions and expectations given to 140 nurses. The results showed that perception of nurses tend to agree with an average value of 93,81\% for the opinion and for the expectation of 98,16\%. The conclusion that the nurse had good opinions and expectation to the role of pharmacists in accordance with Pharmaceutical Care Standards.
\end{abstract}

Key words : Pharmaceutical Care, Nurse Perception, Pharmacists.

\begin{abstract}
ABSTRAK
Pelayanan farmasi merupakan salah satu kegiatan penunjang pelayanan kesehatan yang bermutu. Sebagian besar Rumah Sakit di Indonesia belum melakukan kegiatan pelayanan farmasi sesuai dengan Standar Pelayanan Kefarmasian di Rumah Sakit yang diatur dalam Peraturan Menteri Kesehatan Republik Indonesia No. 72 Tahun 2016. Kurangnya kerjasama dan komunikasi antara apoteker, perawat dan tenaga kesehatan lain dapat menyebabkan perbedaan persepsi. Penelitian ini bertujuan untuk mengetahui pendapat dan harapan perawat terhadap peran apoteker dalam pelayanan kefarmasian di Rumah Sakit Robert Wolter Mongisidi Manado. Penelitian ini merupakan penelitian deskriptif kuantitatif dan alat pengumpulan data yang digunakan berupa kuesioner tentang pendapat dan harapan yang diberikan kepada 140 perawat. Hasil penelitian menunjukkan bahwa persepsi perawat cenderung setuju dengan nilai rata-rata untuk pendapat sebesar 93,81\% dan untuk harapan sebesar $98,16 \%$. Kesimpulan yang didapat bahwa perawat memiliki pendapat dan harapan yang baik terhadap peran apoteker sesuai dengan Standar Pelayanan Kefarmasian.
\end{abstract}

Kata kunci : Pelayanan Kefarmasian, Persepsi Perawat, Apoteker. 


\section{PENDAHULUAN}

Upaya kesehatan adalah suatu kegiatan untuk memelihara, meningkatkan dan mewujudkan derajat kesehatan yang optimal bagi masyarakat. Salah satu sarana pelayanan kesehatan yang berperan penting dalam mendukung upaya tersebut ialah rumah sakit. Rumah sakit adalah salah satu sarana kesehatan yang merupakan rujukan pelayanan kesehatan dengan fungsi utama menyelenggarakan upaya kesehatan yang bersifat penyembuhan dan pemulihan bagi pasien. Di rumah sakit juga terdapat pelayanan farmasi yang merupakan salah satu kegiatan penunjang pelayanan kesehatan yang bermutu (Depkes RI, 2004).

Sejalan dengan perkembangan ilmu pengetahuan dan teknologi dibidang kefarmasian telah terjadi pergeseran orientasi pelayanan kefarmasian dari pengelolaan obat sebagai komoditi kepada pelayanan yang komprehensif (pharmaceutical care). Dalam pengertian tidak saja sebagai pengelola obat namun dalam pengertian yang lebih luas mencakup pelaksanaan pemberian informasi untuk mendukung penggunaan obat yang benar dan rasional, monitoring penggunaan obat untuk mengetahui tujuan akhir, serta kemungkinan terjadinya kesalahan pengobatan (Kemenkes RI, 2016). Konsekuensi dari perubahan orientasi tersebut apoteker dituntut untuk meningkatkan pengetahuan, keterampilan dan perilaku untuk dapat berinteraksi langsung dengan pasien serta harus mampu bekerja sama dengan tenaga kesehatan lainnya termasuk perawat untuk memberikan terapi yang optimal bagi pasien. Bentuk interaksi tersebut antara lain apoteker harus memberikan informasi yang benar, jelas dan mudah dimengerti, akurat, tidak bias, etis, bijaksana dan terkini. Informasi obat pada pasien sekuragkurangnya meliputi cara pemakaian obat, cara penyimpanan obat, jangka waktu pengobatan, aktivitas serta makanan dan minuman yang harus dihindari selama terapi.

Penelitian tentang persepsi perawat terhadap peran apoteker di Indonesia belum banyak dilakukan. Penelitian dengan topik serupa pernah dilakukan oleh Pusparini (2012) di kota Surabaya, yaitu tentang persepsi perawat terhadap peran apoteker yang bekerja di Puskesmas. Penelitian tersebut menunjukkan bahwa ditinjau dari aspek pengalaman perawat terhadap peran apoteker di Puskesmas sudah cukup baik sedangkan bila ditinjau dari aspek penerimaan perawat terhadap peran apoteker secara umum termasuk kategori cukup baik. Pada pernyataan "Apoteker harus diberi hak untuk melakukan perubahan pada obat yang diresepkan yang dapat merugikan pasien" sebagian perawat memiliki persepsi kurang setuju dengan pernyataan tersebut. Pernyataan tersebut menunjukkan bahwa masih terdapat perbedaan persepsi dikalangan perawat dengan apoteker, dimana sesuai teori menyatakan bahwa apoteker dapat mengganti obat berdasarkan persetujuan dari dokter dan pasien yang bersangkutan. Berdasarkan uraian latar belakang diatas peneliti merasa perlu adanya penelitian tentang persepsi perawat terhadap peran apoteker dalam pelayanan kefarmasian di Rumah Sakit Robert Wolter Mongisidi Manado.

\section{METODOLOGI PENELITIAN}

\section{Waktu dan Tempat Penelitian}

Penelitian ini dilaksanakan pada bulan Desember 2019 - Juni 2020 di Rumah Sakit Robert Wolter Mongisidi Manado.

\section{Jenis Penelitian}

Penelitian ini merupakan penelitian deskriptif kuantitatif. Penelitian deskriptif adalah suatu penelitian yang bertujuan untuk menggambarkan atau memaparkan sesuatu hal misalnya keadaan, kondisi, situasi dan peristiwa kegiatan. Penelitian kuantitatif adalah metode penelitian yang berbentuk angka-angka mulai dari pengumpulan data, penafsiran terhadap data tersebut serta penampilan dari hasilnya (Arikunto, 2006). 


\section{Alat dan Bahan}

Alat

Alat yang digunakan dalam penelitian ini adalah alat tulis menulis, lembar kuesioner, dan kamera untuk dokumentasi.

\section{Bahan}

Bahan yang digunakan dalam penelitian ini terdiri dari dua data yaitu:

1. Data Primer

Data primer yang digunakan dalam penelitian ini diperoleh dari kuesioner yang diisi oleh responden.

2. Data Sekunder

Data sekunder yang digunakan dalam penelitian ini adalah studi bahan kepustakaan berupa jurnal dan artikel penelitian yang perlu untuk mendukung data primer.

\section{Populasi Penelitian}

Populasi adalah wilayah generalisasi yang terdiri atas subjek atau objek yang mempunyai kualitas dan karakteristik tertentu yang ditetapkan oleh peneliti untuk dipelajari dan kemudian ditarik kesimpulan (Sugiyono, 2016). Populasi dalam penelitian ini adalah perawat yang bekerja di Rumah Sakit Robert Wolter Mongisidi Manado.

\section{Sampel Penelitian}

Sampel yang digunakan dalam penelitian ini yaitu perawat yang bekerja di Rumah Sakit Robert Wolter Mongisidi Manado yang memenuhi kriteria inklusi dan eksklusi sebagai berikut:

1. Kriteria inklusi
a. Perawat yang bersedia menjadi responden

2. Kriteria eksklusi

a. Perawat yang memiliki hubungan kekerabatan dengan apoteker di Rumah Sakit Robert Wolter Mongisidi Manado

b. Responden yang tidak selesai mengisi kuesioner

Besaran sampel dalam penelitian ini diukur dengan menggunakan Rumus Slovin (Narimawati, 2010) adalah sebagai berikut:

$$
n=\frac{N}{1+N e^{2}}
$$

Keterangan:

$\mathrm{n}=$ Jumlah sampel yang diambil

$\mathrm{N}=$ Jumlah populasi

$\mathrm{e}=$ Presentase kesalahan sampel, $\mathrm{e}=0,05$ $(5 \%)$

Perhitungan tersebut menunjukkan bahwa minimal sampel yang digunakan dalam penelitian ini berjumlah 138 responden.

\section{Pengumpulan Data}

Pengambilan data penelitian dilakukan dengan cara peneliti menyebarkan kuesioner kepada perawat di Rumah Sakit Robert Wolter Mongisidi Manado. Kuesioner yang digunakan pada penelitian ini, disusun berdasarkan modifikasi skala likert yaitu dengan mengubah 5 alternatif jawaban menjadi 4 alternatif jawaban. Kuesioner yang telah selesai diisi oleh responden kemudian dikumpulkan untuk selanjutnya diolah.

\section{Analisis Data}

Kuesioner yang digunakan dalam penelitian ini dilakukan pembobotan dengan menggunakan skala Likert yaitu sebagai berikut:

1. Jawaban sangat setuju diberi bobot 4

2. Jawaban setuju diberi bobot 3

3. Jawaban tidak setuju diberi bobot 2 , dan

4. Jawaban sangat tidak setuju diberi bobot 1

Kuesioner yang telah terisi dengan jawaban responden dan dinyatakan telah memenuhi kriteria penelitian selanjutnya dianalisis. Data uji validitas dan eliabilitas dianalisis menggunakan program aplikasi statistik sedangkan data hasil kuesioner terlebih dahulu dikelompokkan dan dihitung jumlah responden dengan jawaban yang sama pada tiap pertanyaan. Data tersebut kemudian dianalisis menggunakan program excel dengan rumus sebagai berikut:

$$
\begin{aligned}
& \% \text { Pendapat }=\frac{\text { jumlah Responden } \times \text { Bobot }}{\text { Total Responden } \times \text { Bobot }} \times 100 \\
& \text { dan } \\
& \% \text { Harapan }=\frac{\text { Jumlah Responden } \times \text { Bobot }}{\text { Total Responden } \times \text { Bobot }} \times 100
\end{aligned}
$$


HASIL DAN PEMBAHASAN

Karakteristik Responden

Tabel 1. Karakteristik Responden

\begin{tabular}{|c|c|c|}
\hline \multirow[t]{2}{*}{ Karakteristik } & \multicolumn{2}{|c|}{ Total } \\
\hline & n & $(\%)$ \\
\hline \multicolumn{3}{|l|}{ Jenis Kelamin } \\
\hline Laki-laki & 33 & 23.57 \\
\hline Perempuan & 107 & 76.43 \\
\hline \multicolumn{3}{|l|}{$\begin{array}{c}\text { Usia (Depkes, } \\
\text { 2009) }\end{array}$} \\
\hline 17 - 25 Tahun & 46 & 32.86 \\
\hline 26 - 35 Tahun & 80 & 57.14 \\
\hline 36 - 45 Tahun & 14 & 10 \\
\hline 46 - 56 Tahun & 0 & 0 \\
\hline 56 - 65 Tahun & 0 & 0 \\
\hline > 65 Tahun & 0 & 0 \\
\hline \multicolumn{3}{|l|}{ Lama Bekerja } \\
\hline$<1$ Tahun & 6 & 4.29 \\
\hline 1 - 5 Tahun & 88 & 62.85 \\
\hline 5-10 Tahun & 41 & 29.29 \\
\hline$>10$ Tahun & 5 & 3.57 \\
\hline
\end{tabular}

Keterangan: $\mathrm{n}=$ Jumlah Perawat

$$
\%=\text { Persentase }
$$

Karakteristik responden dalam penelitian ini dibagi berdasarkan jenis kelamin, usia dan lama bekerja. Pada Tabel 1 dapat dilihat bahwa responden terbanyak didominasi oleh kelompok perempuan yaitu sebanyak $76,43 \%$. Penelitian yang dilakukan oleh Sanz de Acedo et al (2007) menyatakan bahwa terdapat perbedaan yang signifikan antara laki-laki dan perempuan dalam mengambil suatu keputusan. Pada karakteristik usia, diketahui bahwa responden terbanyak berada dalam rentang usia 26-35 tahun. Usia dapat mempengaruhi daya tangkap dan pola fikir seseorang. Semakin bertambahnya usia maka akan semakin berkembang kemampuan intelektual, pemecahan masalah dan kemampuan verbalnya. Oleh sebab itu, usia dapat mempengaruhi seseorang dalam memberikan suatu keputusan (Widodo,2016). Menurut As'ad (2000), lama masa kerja dapat mempengaruhi tingkat pengetahuan masingmasing profesi. Penelitian ini menunjukkan bahwa responden terbanyak telah bekerja selama 1-5 tahun. Hasil tersebut sesuai dengan teori yang dinyatakan oleh Simanjuntak (1985), bahwa semakin lama seseorang bekerja maka semakin banyak pengalaman dan semakin tinggi pengetahuan serta keterampilannya. Seseorang yang telah bekerja lebih lama dapat memberikan suatu keputusan yang lebih bijak dari pada yang baru bekerja.

\section{Analisis Deskriptif Persepsi Perawat Terhadap Peran Apoteker}

Persepsi perawat terhadap peran apoteker dalam pelayanan kefarmasian yang diukur dalam penelitian ini terdiri dari 2 kategori yaitu pendapat dan harapan. Tabel 2 menunjukkan distribusi jawaban responden terhadap 18 item pernyataan tentang pendapat sedangkan tabel 3 menunjukkan distribusi jawaban responden terhadap 7 item pernyataan tentang harapan. 
Tabel 2. Pendapat perawat terhadap peran apoteker dalam pelayanan kefarmasian

\section{No Pernyataan}

1 Apoteker adalah sebuah profesi yang menekuni ruang lingkup obat dan bertanggung jawab penuh pada pelayanan obat dan alat kesehatan

2 Apoteker pada perkembangannya harus mulai berorientasi pada pasien lebih dari berorientasi pada produk

3 Apoteker harus memberikan perhatian kepada kesejahteraan pasien dengan segala aspeknya

4 Apoteker bertanggung jawab dalam memantau penggunaan obat baik pada pasien rawat inap maupun pasien rawat jalan

5 Apoteker bertanggung jawab dalam menganalisis efektifitas biaya

6 Apoteker harus ikut bertanggung jawab dalam penyusunan formularium obat

7 Apoteker harus dapat berkomunikasi dengan perawat dan tenaga medis lain, serta berpartisipasi dalam membahas masalah terapi yang diberikan pada pasien

8 Apoteker harus mendokumentasi setiap kegiatan untuk dilakukan evaluasi terhadap pelayanan kefarmasian

9 Apoteker harus terlibat langsung dalam perumusan segala keputusan yang berhubungan dengan pelayanan farmasi dan penggunaan obat

10 Apoteker bertanggung jawab dalam memberikan informasi mengenai obat kepada perawat dan tenaga medis lain

11 Apoteker harus bertanggung jawab mengenai masalah yang berkaitan dengan penggunaan obat (drugs related problem)

12 Apoteker bertanggung jawab dalam pemantauan kadar obat dalam darah (terapeutic drugs monitoring)

13 Apoteker harus menangani pencampuran obat suntik

14 Apoteker harus menangani nutrisi parenteral

\begin{tabular}{lll}
\multicolumn{3}{l}{ Jawaban Responden (\%) } \\
\hline SS S TS STS
\end{tabular}

$67,14 \quad 32,14 \quad 0,71 \quad 0$

Kecenderungan

$\mathrm{S}(\mathrm{SS}+\mathrm{S}) / \mathrm{TS}$

(TS+STS)

Setuju

$\begin{array}{ccccc}55 & 40 & 5 & 0 & \text { Setuju } \\ 47,86 & 47,86 & 2,86 & 1,43 & \text { Setuju } \\ 52,86 & 44,29 & 2,86 & 0 & \text { Setuju }\end{array}$

$\begin{array}{lllll}33,57 & 47,86 & 15,71 & 2,86 & \text { Setuju }\end{array}$

$\begin{array}{lllll}57,14 & 42,86 & 0 & 0 & \text { Setuju }\end{array}$

$\begin{array}{lllll}59,29 & 40,71 & 0 & 0 & \text { Setuju }\end{array}$

$62,14 \quad 37,14 \quad 0,71 \quad 0 \quad$ Setuju

$\begin{array}{lllll}64,29 & 35 & 0,71 & 0 & \text { Setuju }\end{array}$

$55 \quad 44,29 \quad 0,71 \quad 0 \quad$ Setuju

$69,29 \quad 30,71 \quad 0 \quad 0 \quad$ Setuju

$40,71 \quad 46,43 \quad 12,86 \quad 0 \quad$ Setuju

$34,29 \quad 47,14 \quad 16,43 \quad 2,14 \quad$ Setuju

$\begin{array}{lllll}26,43 & 52,86 & 19,29 & 1,43 & \text { Setuju }\end{array}$ 


\begin{tabular}{|c|c|c|c|c|c|c|}
\hline \multirow[t]{2}{*}{ No } & \multirow[t]{2}{*}{ Pernyataan } & \multicolumn{4}{|c|}{ Jawaban Responden (\%) } & \multirow{2}{*}{$\begin{array}{c}\text { Kecenderungan } \\
\text { S }(\mathrm{SS}+\mathrm{S}) / \mathrm{TS} \\
(\mathrm{TS}+\mathrm{STS})\end{array}$} \\
\hline & & $\mathrm{SS}$ & $\bar{S}$ & $\mathrm{TS}$ & STS & \\
\hline 15 & $\begin{array}{l}\text { Apoteker harus menangani obat } \\
\text { kanker atau sitostatistika }\end{array}$ & 37,14 & 54,29 & 8,57 & 0 & Setuju \\
\hline 16 & $\begin{array}{l}\text { Apoteker dapat mengakses penyakit } \\
\text { dan riwayat pengobatan pasien dalam } \\
\text { rekam medis untuk memantau } \\
\text { penggunaan obat yang rasional }\end{array}$ & 38,57 & 48,57 & 12,86 & 0 & Setuju \\
\hline 17 & $\begin{array}{l}\text { Apoteker perlu memberikan konseling } \\
\text { obat baik pada pasien rawat inap } \\
\text { maupun pasien rawat jalan }\end{array}$ & 52,86 & 45 & 2,14 & 0 & Setuju \\
\hline 18 & $\begin{array}{l}\text { Keterlibatan apoteker seperti yang } \\
\text { telah disebutkan di atas sangat } \\
\text { membantu perawat dan staf medis lain } \\
\text { dalam memaksimalkan proses terapi }\end{array}$ & 62,14 & 35,71 & 2,14 & 0 & Setuju \\
\hline
\end{tabular}

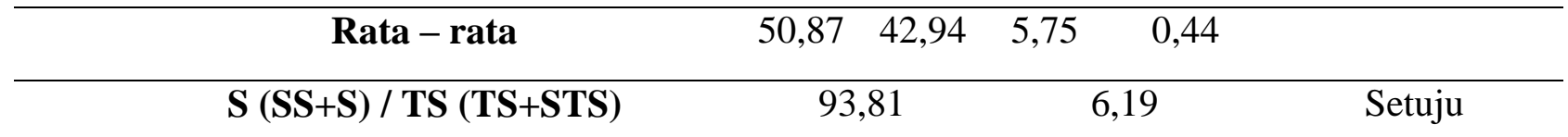

Tabel 2 menunjukkan bahwa sebagian besar responden cenderung setuju dengan pernyataan yang diberikan mengenai peran apoteker dalam pelayanan kefarmasian dengan nilai rata-rata yang diperoleh yaitu sebanyak 93,81\%. Pernyataan dalam kuesioner tersebut dibuat berdasarkan Peraturan Menteri Kesehatan Republik Indonesia No. 72 Tahun 2016 Tentang Standar Pelayanan Kefarmasian di Rumah Sakit.

Hasil penelitian menunjukkan bahwa $15,71 \%$ responden tidak setuju apabila apoteker bertanggung jawab dalam menganalisis efektifitas biaya. Jawaban tersebut dikarenakan responden baeranggapan bahwa yang bertanggung jawab dalam menganalisis efektivitas biaya pengobatan pasien dilakukan oleh dokter pada saat pemilihan obat dalam peresepan. Sebanyak $12,86 \%$ responden tidak setuju apabila apoteker melakukan pemantauan obat dalam darah (terapeutic drugs monitoring). Responden belum mengetahui adanya kegiatan pemantauan kadar obat dalam darah yang dilakukan oleh apoteker karena selama ini kegiatan pemantauan kadar obat dalam darah belum dilaksanakan di Rumah Sakit tersebut. Responden juga tidak mengetahui peran penting dan manfaat dari keterlibatan apoteker dalam kegiatan pemantauan kadar obat dalam darah.

Responden sebanyak 16,43\% tidak setuju apabila apoteker bertanggung jawab terhadap pencampuran obat suntik dan $8,57 \%$ responden tidak setuju apabila apoteker harus menangani obat sitostatika. Apoteker perlu mensosialisasikan perannya dalam hal penanganan pencampuran obat suntik juga penanganan sitostatika dan lebih banyak berdiskusi bersama perawat dan tenaga kesehatan lain mengenai penanganan obat suntik dan sitostatika agar tenaga kesehatan lain dapat memahami peran penting apoteker dalam kegiatan tersebut.

Responden yang tidak setuju apabila apoteker dapat mengakses penyakit dan riwayat pengobatan pasien dalam rekam medis sebanyak $12,86 \%$. Responden beranggapan bahwa yang berhak mengakses riwayat penyakit dan pengobatan pasien dalam rekam medik adalah dokter, mengingat isi rekam medik harus dijaga kerahasiannya. Tujuan apoteker mengakses riwayat pengobatan dalam rekam medis adalah untuk melakukan assessment penggunaan obat untuk memastikan apakah obat yang digunakan pasien tepat dan aman. 
Tabel 3. Harapan perawat terhadap peran apoteker dalam pelayanan kefarmasian

No Pernyataan

1 Saya berharap apoteker memiliki pengetahuan yang luas mengenai obat dan terapi obat

2 Saya berharap peran apoteker dapat ditingkatkan lagi dalam memberikan pelayanan yang lebih berorientasi kepada pasien

3 Saya berharap apoteker dapat berperan lebih aktif dalam penilaian pasien yang kemungkinan terdapat masalah terkait obat (drug related problem)

4 Saya berharap apoteker harus dapat menyesuaikan terapi obat pada pasien (pasien penyakit kronis) menggunakan protokol yang telah di setujui oleh dokter

5 Saya berharap apoteker dapat berperan aktif dalam memantau, mengikuti perkembangan dan mendokumentasikan respon pasien terhadap terapi pengobatannya

6 Saya berharap apoteker berperan lebih aktif dalam memberi konseling pada pasien tentang penggunaan obat yang tepat

7 Saya berharap apoteker dapat mendampingi dokter ketika menangani pasien

\begin{tabular}{|c|c|}
\hline Jawaban Re & \\
\hline $\mathrm{TS} \quad \mathrm{S}$ & $\begin{array}{c}\text { S(SS+S)/TS } \\
(\mathrm{TS}+\mathrm{STS})\end{array}$ \\
\hline
\end{tabular}

$80,71 \quad 19,29 \quad 0 \quad 0$

Setuju

$\begin{array}{lllll}75 & 25 & 0 & 0 & \text { Setuju }\end{array}$

$68,57 \quad 30,71 \quad 0,71 \quad 0 \quad$ Setuju

$58,57 \quad 41,43 \quad 0 \quad 0 \quad$ Setuju

$\begin{array}{lllll}57,14 & 42,86 & 0 & 0 & \text { Setuju }\end{array}$

$66,43 \quad 33,57 \quad 0 \quad 0 \quad$ Setuju

$53,57 \quad 34,29 \quad 11,43 \quad 0,71 \quad$ Setuju $\begin{array}{llll}65,71 & 32,45 & 1,73 & 0,10\end{array}$

\begin{tabular}{cccc}
\hline $\mathbf{S}(\mathbf{S S}+\mathbf{S}) / \mathbf{T S}(\mathbf{T S}+\mathbf{S T S})$ & 98,16 & 1,83 & Setuju \\
\hline
\end{tabular}

Tabel 3 menunjukkan bahwa mayoritas responden setuju apabila apoteker dapat melaksanakan perannya sesuai dengan Standar Pelayanan Kefarmasian di Rumah Sakit dengan nilai rata-rata yang diperoleh sebanyak 96,16\%. Penelitian ini menunjukkan bahwa sebanyak $11,43 \%$ responden tidak setuju jika apoteker mendampingi dokter ketika menangani pasien. Responden beranggapan bahwa kegiatan penanganan pasien merupakan pekerjaan dan wewenang dokter. Apoteker memiliki peran dan tanggung jawab yang berbeda dengan dokter dalam hal penanganan pasien sehingga tidak mungkin mengambil alih tugas dokter. Penanganan pasien yang dilakukan oleh apoteker pada saat mendampingi dokter hanya bertugas untuk memastikan penggunaan obat yang rasional bagi pasien dan memantau 
terapi untuk menjamin efektivitas dan keamanannya.

\section{KESIMPULAN}

Kesimpulan yang didapat bahwa persepsi perawat yang terdiri dari pendapat dan harapan terhadap peran apoteker dalam pelayanan kefarmasian di Rumah Sakit Robert Wolter Mongisidi Manado cenderung setuju dengan nilai rata-rata untuk pendapat sebesar $93,81 \%$ dan untuk harapan sebesar 98,16\%. Hasil tersebut menunjukkan bahwa perawat memiliki pendapat dan harapan yang baik terhadap peran apoteker sesuai dengan Standar Pelayanan Kefarmasian di Rumah Sakit.

\section{SARAN}

Disarankan bagi peneliti selanjutnya untuk melakukan penelitian tentang evaluasi penerapan standar pelayanan kefarmasian di Rumah Sakit Robert Wolter Mongisidi Manado.

\section{DAFTAR PUSTAKA}

Arikunto, S. 2006. Prosedur Penelitian Suatu Pendekatan Praktik. Rineka Cipta, Jakarta.

As'ad, M. 2000. Psikologi Industri edisi 4. Liberty, Yogyakarta.

Departemen Kesehatan Republik Indonesia. 2004. Keputuasan Menteri Kesehatan Nomor 1197/Menkes/SK/X/2004 Tentang Standar Pelayanan Farmasi Di Rumah Sakit. Departemen Kesehatan Republik Indonesia., Jakarta.

Departemen Kesehatan Republik Indonesia. 2009. Kategori Umur. Departemen Kesehatan Republik Indonesia, Jakarta.

Kementrian Kesehatan Republik Indonesia. 2016. Peraturan Menteri Kesehatan RI Nomor 72 Tahun 2016 Tentang Standar Pelayanan Kefarmasian Di Rumah Sakit. Kementrian Kesehatan Republik Indonesia, Jakarta
Narimawati, U. 2010. Metodelogi Penelitian: Dasar Penyusunan Penelitian Ekonomi. Genesis, Jakarta.

Pusparini, R. 2012. Persepsi Perawat Terhadap Peran Apoteker Dalam Pelayanan Kefarmasian Puskesmas Wilayah Surabaya Timur [skripsi]. Fakultas Farmasi Ubaya, Surabaya.

Regziana, D. 2007. Pendapat Dokter Umum di Rumah Sakit Daerah di Daerah Istimewa Yogyakarta Terhadap Peran Apoteker (Berdasarkan Keputusan Menteri Kesehatan Nomor 1197/Menkes/SK/X/2004 Tentang Standar Pelayanan Kefarmasian di Rumah Sakit) [Skripsi]. Fakultas Farmasi Universitas Sanata Dharma, Yogyakarta.

Sanz de Acedo, L. M. L., Sanz de Acedo, B. M. T., Cardelle-Elawar, y M. 2007. Factors that affect decision making: gender and age differences. International Journal of Psychology and Psychological Therapy. 7(3): 381391.

Simanjuntak, P. J. 1985. Pengantar Ekonomi Sumber Daya Manusia. Fakultas Ekonomi Universitas Indonesia, Jakarta.

Sugiyono. 2016. Metode Penelitian Kuantitatif, Kualitatif dan $R \& D$. Alfa Beta, Bandung.

Widodo. 2016. Faktor-Faktor Yang Berhubungan Dengan Pengetahuan Perawat Tentang Penatalaksanaan Asuhan Keperrawatan Pasien Dekompensasi Kordis Di Ruang ICVCU RSUD. Dr.Moewardi. Jurnal Keperawatan Global. 2(1): 55-103. 